\title{
Spatial and seasonal variability in the relationships between benthic communities and physical environment in a lagoon ecosystem
}

\author{
Bertrand Millet ${ }^{1}$, Olivier Guelorget ${ }^{2}$ \\ 'Centre d'Océanologie de Marseille, URA CNRS 41, Université d'Aix-Marseille II, Luminy-Case 901. \\ F-13288 Marseille Cedex 09, France \\ ${ }^{2}$ Laboratoire d'Hydrobiologie Marine, URA CNRS 1355, Université de Montpellier II, Place Eugène Bataillon, \\ F-34095 Montpellier Cedex 05, France
}

\begin{abstract}
Hydrodynamic processes within a shallow Mediterranean lagoon, the Etang du Prévost in southwestern France, are essentially controlled by the combined effects of tide and wind, which induce both horizontal advection and vertical turbulent diffusion. The spatial distribution of macrobenthic organisms within this lagoon varies seasonally, according to variability in the hierarchy of the forcing environmental conditions. A 2-dimensional numerical model is used to compute spatial distributions in the lagoon of the tide- and wind-induced hydrodynamic kinetic energy under typical environmental conditions. An Alternating Conditional Expectation (ACE) algorithm is used to demonstrate non-linear spatial and seasonal relationships in multiple regression between benthic communities and physical environment. Mollusc and crustacean biomasses at 8 sampling stations are considered as dependent variables in the ACE analyses, while the distance of each sampling station from the sea inlet, the granulometry of the upper sediment (fraction of fine particles below $40 \mu \mathrm{m}$ ), and the computed tide- or windinduced kinetic energy are considered successively as predictors. Results provide insight into the relationships between benthic macrofauna and sediment or hydrodynamic features, and especially into the spatial and seasonal variability of these relationships. Spatially, results emphasize the distinction between the optimal development of molluscs, associated with the energetic physical environment prevailing at seaward locations, and that of crustaceans associated with the more confined environment prevailing landwards. In addition, a distance of $1.6 \mathrm{~km}$ from the sea inlet is computed and proposed as the maximum spatial extension in the inner lagoon of a specific marine influence. Temporally, the major contributions of distance from the sea inlet, granulometry and tide-induced hydrodynamics, in regressions from January to May, confirm the central role of sediment features and tidal impact in explaining the seasonal variability of benthic macrofauna from winter to spring, related to the recruitment dynamics of marine larvae. Also seasonally, the increasing efficiency as a predictor of tide-induced kinetic energy from May to October supports a beneficial impact of marine water circulation on benthic macrofauna in preventing, at seaward locations, the anoxia which prevails in the inner lagoon in summer.
\end{abstract}

KEY WORDS: Lagoon - Mollusc - Crustacean - Granulometry - Kinetic energy - Statistical analysis Hydrodynamic model

\section{INTRODUCTION}

Hydrodynamic processes in lagoons are essentially controlled by external energy inputs from tide or wind stresses, which induce both horizontal advective dispersion and turbulent vertical exchanges within the water masses (Kullenberg 1978). However the spatial pattern, seasonal dynamics and biological efficiency of horizontal and vertical physical processes are quite different according to whether the dominant forcing function is the wind or the tide.

Previous studies have clearly demonstrated the central role of tide- and wind-induced physical processes in the control of phytoplankton dynamics (Levasseur et 


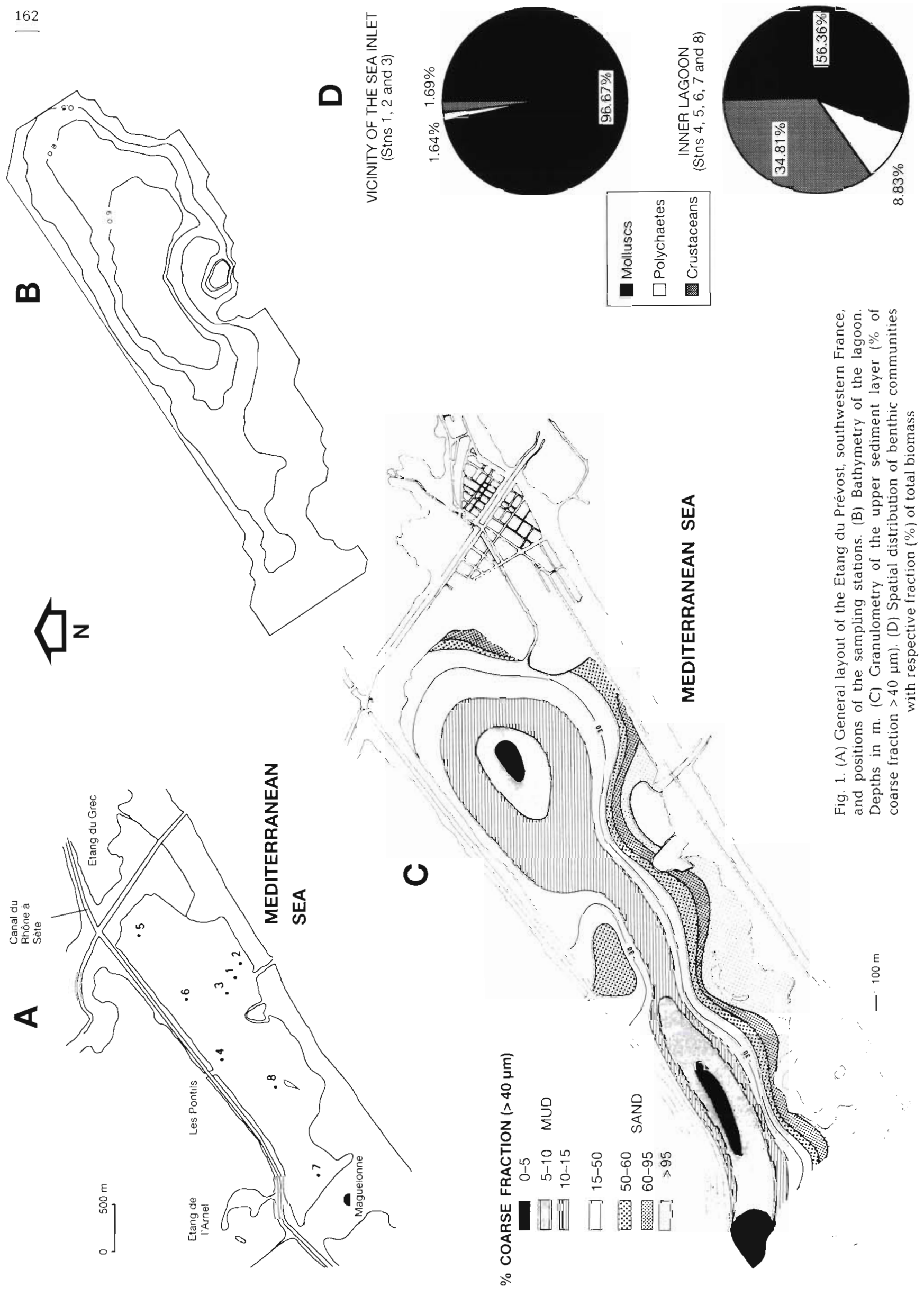


al. 1983, 1984), and non-linear relationships, especially between plankton biomass and wind-induced circulation, have been demonstrated in the Mediterranean lagoon of Thau (Millet \& Cecchi 1992). In parallel, the major role of tide-and wind-induced processes in the control of the time-space dynamics of benthic communities was confirmed (Emerson 1990, Hamerlynck \& Mees 1991), and non-linear relationships between benthic biomass and wind-induced horizontal dispersion have recently been suggested, also for the Thau lagoon (Millet \& Guelorget 1993).

Multidisciplinary studies in various Mediterranean lagoons have provided evidence of an organizational and functional pattern in these coastal systems, corresponding to the optimal reaction of benthic organisms to fit in with their physical environment. As a result, there is one feature in common as regards the spatial distribution of macrobenthic communities in all Mediterranean lagoon systems, whether these are very shallow, very deep, brackish or very salty, namely that there is a succession of benthic species determined by distance from the sea (Guelorget \& Perthuisot 1983, 1992).

This concept of isolation from the sea emphasizes the ecological relevance of the relationships between spatial distribution of organisms and movements of marine water within the system. Therefore, it is of interest to obtain further insight into the ecological impact of the major hydrodynamic processes involved in the circulation of water masses from the sea inlet to the inner lagoon (marine water renewal).

The present study was performed in the lagoon of Etang du Prévost, located near the lagoon of Thau previously mentioned, but differing by being very shallow, which is likely to reinforce barotropic tidal velocities (inversely proportional to the volumes of water involved), as opposed to vertically sheared windinduced motions (independent of volume). The benthic communities were previously described (Guelorget \& Michel 1979a, b, Amanieu et al. 1980), but a new approach, focusing on the space-time variability of biomass in relation to both tide- and wind-induced physical processes, provides a closer insight into the relative significance of tide- or wind-forced dynamics.

A numerical model was therefore necessary to compute the main hydrodynamic features spatially over the whole area, while allowing a clear dinstinction between tidal input or wind-stress forcing. Using an Alternating Conditional Expectations (ACE) statistical algorithm, seasonal changes in biomasses of molluscs and crustaceans recorded during 3 surveys carried out in October 1973 and January and May 1974 are regressed against several observed physical descriptors (distance from the sea inlet, granulometry), or computed hydrodynamic predictors (kinetic energy), including a comparison of forcing by only tide and only typical wind condition.

\section{DATA AND METHODS}

Study area. The Etang du Prévost is a shallow lagoon near Montpellier in southwestern France, measuring $3.5 \mathrm{~km}$ in length and $800 \mathrm{~m}$ in width, with an area of about 380 ha, a permanent sea inlet and a small channel, Les Pontils, connecting with the adjacent lagoon, Etang de l'Arnel (Fig. 1A). Depths in the lagoon range from $0.30 \mathrm{~m}$ on the periphery to $1.50 \mathrm{~m}$ in the middle (Fig. 1B).

Sampling design. Analysis of the benthic communities was carried out at 8 stations across the lagoon (Fig. 1A). At each sampling survey (October 1973, January and May 1974) and at each of 8 stations, 5 samples of $0.1 \mathrm{~m}^{2}$ each were collected with an Ekman grab sampler. After sieving on a $2 \mathrm{~mm}^{2}$ mesh vacuum sieve, the sieve residue was treated and fixed with $10 \%$ neutral formaline. Biomass, after drying in an oven, corresponds to dry weights of organic matter in $\mathrm{mg} \mathrm{m}^{-2}$.

Sediment features. The substratum consists essentially of shelly mud, with a variable sand content, and the fine fraction $<40 \mu \mathrm{m}$ ranging from 60 to $80 \%$. The distribution of bed sediments measured by content of particles $>40 \mu \mathrm{m}$ is shown in Fig. $1 \mathrm{C}$. There is a band of sandy mud in the northern half, a band of silty sand in the southern half, a higher sand content in the vicinity of the sea inlet and of the channel between the lagoons, and a higher mud content in low energy areas, in the middle and at the eastern and western ends.

Benthic communities. The spatial structure of the benthic communities is presented in Fig. 1D. One pattern is defined in the vicinity of the sea inlet featuring a large dominance of molluscs, with biomasses averaged yearly from 12 samples (1 sample collected each month) at Stns 1. $2 \& 3$ (Fig. 1A). A second pattern is defined in the inner lagoon, featuring a larger fraction of crustacean biomass, with averaged values collected at Stns $4,5,6,7 \& 8$. Near the sea inlet, mollusc communities are dominated by Ruditapes aureus, $R$. decussatus, Scrobicularia plana, and Loripes lacteus, and Donax trunculus, D. semistriatus, Tellina tenuis, Mactra glauca, Venus gallina, V. verrucosa, and Acanthocardia echinata are also present. In the inner lagoon, molluscs are exclusively represented by Cerastoderma glaucum and Abra ovata, whereas crustaceans are represented by typical lagoonal species as Gammarus insensibilis, $G$. aequicauda, Corophium insidiosum, Idotea baltica, Sphaeroma hookeri and Carcinus mediterraneus.

Hydrodynamic model. A 2-dimensional numerical model of the vertically averaged circulation was 
applied to the lagoon. The model computes windinduced and tide-induced currents and elevations, according to lagoon bathymetry, wind stress, tidal input and bottom friction. The Coriolis force (weak), and the non-linear advection terms are both taken into account. The advection terms are used in preference to the terms of horizontal turbulent viscosity, and the vertical turbulent viscosity is treated globally by the use of the terms of surface wind shear and bottom friction. The use of a 2-dimensional model is justified by the shallowness of the lagoon, and by the absence of thermal or saline stratification. The equations of the model are as follows:

$\delta U / \delta t+U \delta U / \delta x+V \delta U / \delta y-f V+g \delta \zeta / \delta x-\tau_{s x} / \rho H+\tau_{b x} / \rho H=0$

$\delta V / \delta t+U \delta V / \delta x+V \delta V / \delta y+f U+g \delta \zeta / \delta y-\tau_{s y} / \rho H+\tau_{b y} / \rho H=0$ $\delta \zeta / \delta t+\delta(H U) / \delta x+\delta(H V) / \delta y=0$

where:

$\tau_{s x}$ and $\tau_{s y}$ are the components according to the horizontal directions of wind stress:

$$
\tau_{s x}=C_{\mathrm{d}} \rho_{\mathrm{a}} W^{2} \sin \alpha \text { and } \tau_{s y}=C_{\mathrm{d}} \rho_{\mathrm{a}} W^{2} \cos \alpha
$$

$\tau_{b x}$ and $\tau_{b y}$ are the components according to the horizontal directions of bottom stress:

$$
\begin{gathered}
\tau_{b x}=\left[\rho g U\left(U^{2}+V^{2}\right)^{1 / 2}\right] / C^{2} \text { and } \\
\tau_{b y}=\left[\rho g V\left(U^{2}+V^{2}\right)^{1 / 2}\right] / C^{2}
\end{gathered}
$$

$U$ and $V$ are the velocity components according to the horizontal directions

$f=2 \omega \sin \lambda$ is the Coriolis parameter

$\omega$ is angular speed of earth's rotation

$\lambda$ is latitude

$\zeta$ is elevation of the water level

$H$ is depth of the water column

$\rho$ is water density (constant)

$g$ is acceleration due to gravity

$C_{d}$ is wind-drag coefficient

$\rho_{\mathrm{a}}$ is air density

$\alpha$ is wind-direction (constant)

$W$ is wind velocity

$C$ is Chézy bottom stress coefficient

The equations are solved in finite difference form with a classical ADI (Alternating Direction Implicit) numerical scheme using a $50 \mathrm{~m}$ grid and a $10 \mathrm{~s}$ timestep (Leendertse 1984, Millet 1989). The tide-induced and wind-induced hydrodynamic movements are computed separately, to distinguish between ecological features of each forcing function.

Statistical analysis. An ACE iterative algorithm, developed by Breiman \& Friedman (1985), was used to compute optimal transformations for multiple regressions. The dependent $Y$ variable and every predictor variable $X_{1}, \ldots, X_{\mathrm{p}}$ are replaced by functions $\theta(Y)$, $f_{1}\left(X_{1}\right), \ldots, f_{p}\left(X_{p}\right)$ to maximize the correlation coefficient in the following linear model: $\theta(Y)=f_{1}\left(X_{1}\right)+\ldots+f_{p}\left(X_{p}\right)$.
The ACE algorithm can be considered as a nonparametric method that operates on the joint distribution of a dependent variable $Y$ and predictors $X_{1}, \ldots$, $X_{p}$, but in generalizing classical additive models in including a transformation of the response $Y$. There is a close similarity between ACE and canonical correlation analysis. However, the canonical correlation finds the linear combination of the $X_{p}$ that is maximally correlated with $Y$, while ACE generalizes this by finding the linear combination of transformed $X_{p}$ that is maximally correlated with a transformation of $Y$. This is the reason ACE remains more suitable for investigating non-linear relationships between variables. The ACE procedure computes the 'optimal transformation for regression' that is the unique set of functions $\theta(Y)$ and $f_{i}\left(X_{i}\right)$ quantified by minimizing the squared error loss: $E\left\{\left[\theta(Y)-\Sigma_{1} f_{i}\left(X_{l}\right)\right]^{2}\right\}$.

The alternating estimation procedure first initializes $\theta(Y)=(Y-E(Y)) / \operatorname{var}(Y)^{1 / 2}$, then computes, for fixed $\theta(Y)$ and for each predictor $k$ considered, the minimizing functions $f_{k}\left(X_{k}\right)=E\left\{\theta(Y)-\sum_{i \neq k} f_{i}\left(X_{i}\right) \mid X_{k}\right\}$, and then computes from previous values $f_{i}\left(X_{1}\right)$ the minimizing $\theta(Y)=$ $E\left\{\sum_{i} f_{j}\left(X_{1}\right) \mid Y\right\} / \operatorname{var}\left(\sum_{1} f_{j}\left(X_{1}\right) \mid Y\right\}^{1 / 2}$. The computation continues alternating between these 2 steps until the squared error loss $E\left\{\left[\theta(Y)-\Sigma_{i} f_{i}\left(X_{1}\right)\right]^{2}\right\}$ does not change.

Unlike the traditional approaches, ACE does not require any assumption of an underlying model relating $Y$ to $X_{1}, \ldots, X_{p}$, and the algorithm converges each time to an optimal and single solution, empirically defined without any previous speculation on a given known family of distributions, and computed without ambiguity. In addition, the algorithm converges quite rapidly. Results are expressed by plotting the transformed values versus the original data for each variable considered in the model, enabling direct coincidence between some particular shapes of the transformed functions and the correspondent observations to be shown, and sometimes establishing threshold values. In addition, this representation allows the selection of the predictors to which the dependent variable at each seasonal sampling fits the best. The most explicit criteria considered to identify accurate relationships are not limited to the $\mathrm{R}^{2}$ results, but extended for each predictor to the shape of the smoothed transformations, the stability of these shapes after several attempts and the range between the highest and lowest transformation values. Cury \& Roy (1989), Millet \& Cecchi (1992), and Millet \& Guelorget (1993) have previously used this procedure to emphasize the ecological impact of environmental discontinuities for pelagic fish recruitment or phytoplankton and benthos dynamics in different coastal systems.

In the present study, the ACE method was tested in the Etang du Prévost lagoon to determine the assumed non-linear and seasonal relationships be- 
tween the benthic communities, the granulometry of the upper sediment and tide or wind-induced hydrodynamic features. The mollusc and crustacean biomasses sampled at the 8 stations previously described (Fig. 1) were successively considered as dependent variables in the ACE computations. The hydrodynamic information was summarized by the wind and tide-induced kinetic energy computed at each mesh-location $\left(10^{-1} \mathrm{~N} \mathrm{~m}^{-2}\right)$. Physical descriptors related to the level of vertical turbulent diffusion, locally induced through the water column, were considered as independent variables in the ACE computations. The granulometry of the upper sediment (fraction of fine particles $<40 \mu \mathrm{m}$ ) and the distance of each sampling station from the sea inlet $(\mathrm{km})$ were also considered as predictors in the ACE computations. The distances from the sea inlet were measured by following, between the inlet and the position of each station, the flood-tide trajectories drawn from the current field computed by the numerical model under both tide and wind forcing (see Fig. 3C).

These predictors are not independent of each other and the corresponding correlations were checked on the complete sample (8 values) with the following results:

Tide-ind. kinetic energy/granulometry: $r=-0.829$

Tide-ind. kinetic energy/dist. from sea inlet: $\mathrm{r}=-0.657$

Wind-induced kinetic energy/granulometry: $r=-0.874$

Wind-ind. kinetic energy/dist. from sea inlet: $\mathrm{r}=-0.698$

The correlations computed with kinetic energy versus granulometry are quite significant following $z$ tests at the confidence level $\mathrm{p}=0.05$, whereas correlations computed versus the distance from sea inlet lie just below the limit of significance, that is $r=0.707$. However, kinetic energy and distance from sea inlet have been considered as variables too closely correlated to be introduced simultaneously in an ACE additive model. Therefore, we only used ACE procedures for estimating single predictor models (gránulometry or distance or kinetic energy).

Nevertheless, ACE frequently presents artefacts in low-correlation settings $\left(\mathrm{R}^{2}=30\right.$ to $\left.40 \%\right)$, that lead to the computation of especially well-smoothed parabolic or dome-shaped transformations in samples where no dominant trend can be clearly defined, or in samples with disjoint clusters, either for additive model or single predictor. These artefacts are reinforced in cases of small samples $(\mathrm{n}<20)$ with low-correlated variables, and experience showed that it seems better in these cases to rather consider ACE as a correlation than a regression tool (Tibshirani 1988). In the present study, although the sample considered is very small ( $\mathrm{n}=8$ ), the relevance of the ACE algorithm is reinforced by the high correlations computed $\left(\mathrm{R}^{2}\right.$ values) and slightly curved transformations without dome-shaped artefacts. In addition, we limited the ACE interpretations to the meaning of the seasonal variations of correlation intensities and slope directions in the non-linear monotonous transformed functions. The whole data set considered is reported in Table 1.

\section{RESULTS}

\section{Hydrodynamic modelling}

First, a simulation of the tide-induced circulation was run for a $24 \mathrm{~h}$ period. The tidal input was a typical signal recorded in 1988 in the neighbouring harbour of Sète during a period of stability, when the average level was consistent with the mean interannual sea level, and of a range $(34 \mathrm{~cm})$ equal to the mean interannual tidal range for the same station (Fig. $2 \AA$ ). In parallel, a simulation of the wind-induced circulation was run for a $24 \mathrm{~h}$ period. The forcing input was a stationary wind stress of NW $\left(293^{\circ}\right)$ and $8 \mathrm{~m} \mathrm{~s}^{-1}$ (Fig. 2B), which corresponded to the prevailing wind observed during the sampling period, accounting for $20 \%$ of the

Table 1. Benthos data and environmental predictors considered in ACE computations. k.e.: kinetic energy

\begin{tabular}{|c|c|c|c|c|c|c|c|c|c|c|}
\hline \multirow[t]{3}{*}{ Stn } & \multicolumn{6}{|c|}{ Biomass (mg m ${ }^{-2}$ dry organic matter) } & \multicolumn{4}{|c|}{ Environmental predictors } \\
\hline & \multicolumn{3}{|c|}{ Mollusc $\left(\times 10^{3}\right)$} & \multicolumn{3}{|c|}{ Crustacean $\left(\times 10^{2}\right)$} & \multirow{2}{*}{$\begin{array}{c}\text { Granulometry } \\
\text { fraction }<40 \mu \mathrm{m}\end{array}$} & \multirow{2}{*}{$\begin{array}{l}\text { Distance from } \\
\text { sea inlet }(\mathrm{km})\end{array}$} & \multirow{2}{*}{$\begin{array}{l}\text { Wind-ind. ke. } \\
\left(\times 10^{-1} \mathrm{~N} \mathrm{~m}^{-2}\right)\end{array}$} & \multirow{2}{*}{$\begin{array}{l}\text { Tide-ind k.e. } \\
\left(\times 10^{-1} \mathrm{~N} \mathrm{~m}^{-2}\right)\end{array}$} \\
\hline & Jan & May & Oct & Jan & May & Oct & & & & \\
\hline 1 & 410.9 & 502.1 & 117.8 & 17.03 & 0.13 & 1.97 & 4.21 & 0.22 & 172.8 & 229.1 \\
\hline 2 & 23.8 & 73.4 & 77.3 & 5.46 & 4.35 & 4.61 & 25.2 & 0.16 & 113.6 & 115.3 \\
\hline 3 & 37.1 & 34.2 & 23.1 & 22.5 & 12.1 & 7.22 & 33.8 & 0.35 & 108.6 & 36.2 \\
\hline 4 & 5.29 & 26.4 & 0.89 & 44.9 & 0.86 & 1.38 & 27.5 & 1.63 & 40.5 & 4.93 \\
\hline 5 & 4.47 & 8.89 & 3.39 & 28.4 & 68.3 & 0.42 & 61.4 & 2.19 & 52.5 & 0.05 \\
\hline 6 & 16.5 & 22.7 & 13.4 & 101.2 & 22.2 & 29.6 & 68.0 & 0.85 & 1.50 & 1.04 \\
\hline 7 & 19.5 & 13.6 & 7.64 & 104.0 & 76.9 & 0.91 & 61.3 & 3.06 & 18.3 & 0.27 \\
\hline 8 & 8.39 & 12.0 & 21.5 & 21.4 & 32.4 & 8.48 & 62.0 & 1.78 & 34.8 & 4.07 \\
\hline
\end{tabular}




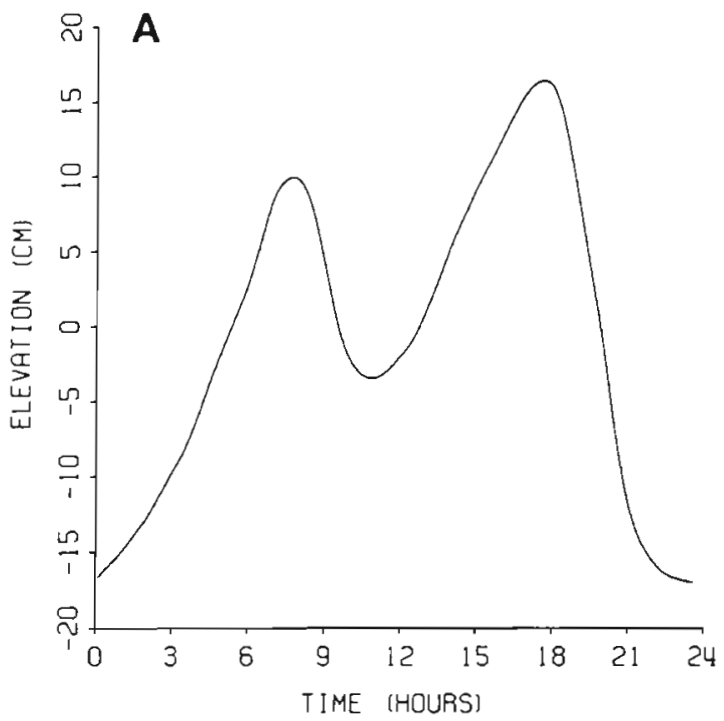

Fig. 2. (A) Typical tidal elevations, recorded in Sète harbour in May 1988, used as tidal input in the numerical model. (B) Local wind regime recorded during the sampling periods (Meteo-France, $10 \mathrm{~m}$ height)
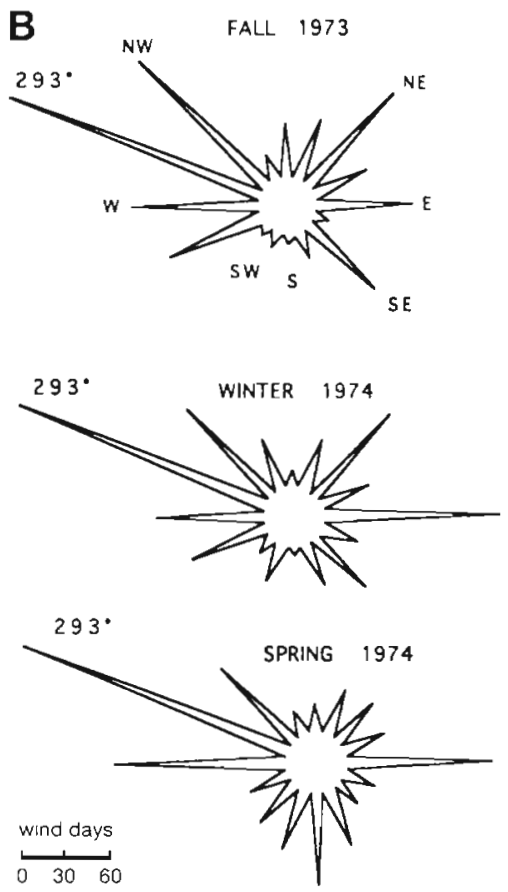

January

time between October 1973 and May 1974. In addition, this observed wind pattern was consistent with the interannual statistical wind regime (1951 to 1980) established for the region by the national office MeteoFrance: NW $\left(290^{\circ}\right)$ accounting for $18 \%$ of the time.

Computed results for tide- and wind-induced current fields are each shown after a $24 \mathrm{~h}$ period of simulation in Fig. 3A \& B, according to the strongest flood tide currents (Fig. 3A) and the dominant situation in the local wind regime (Fig. 3B). Results of a third simulation corresponding to both the tide and wind typical forcings previously described, but acting simultaneously during a 24 h period, are presented in Fig. $3 \mathrm{C}$. The corresponding isolines of kinetic energies computed with tide-only or wind-only forcing are presented in Fig. 4A \& B respectively.

\section{Statistical analysis}

In all the ACE computations, transformations obtained for the dependent variables (biomass) are plotted on the first diagrams of each figure against the original data. Transformations of mollusc (Figs. 5, 7 \& 9) and crustacean (Figs. 6, $8 \& 10$ ) biomasses were in all cases curved with a positive slope, spread over a fairly wide range of values, with good stability from one analysis to another, which means that a good interpretation of the transformations can be obtained with the predictors considered
The ACE algorithm was first applied to the mollusc biomass sampled in January 1974 with the environmental (distance and granulometry) and hydrodynamic (kinetic energy) predictors previously described, and the main results are presented in Fig. 5.

First, transformation of environmental predictors such as the distance from the sea inlet (Fig. 5A) and the granulometry (Fig. 5B) showed in both cases negative curved relationships that respectively explained $54 \%$ and $55 \%$ of the variance. In addition, the negative slope of the transformation of the distance from the sea inlet (Fig. 5A) was steeper below a threshold value of line the importance of the spatial position according to the tidal circulation and the granulometry in the development of the mollusc biomass, which benefits from the proximity of the sea inlet, associated with the coarse fraction of the sediment.

Second, transformations of hydrodynamic predictors such as the tide-induced (Fig. 5C) and wind-induced kinetic energy (Fig. 5D) showed positive relationships that respectively accounted for $85 \%$ and $83 \%$ of the variance. These results indicate that the mollusc biomass benefits from an increase in kinetic energy throughout the water column, in a way that is linear for high values (above $3 \mathrm{~N} \mathrm{~m}^{-2}$ ), and that the behaviour of kinetic energy with regard to mollusc biomass does not appear meaningful for weak values below this limit nor $1.6 \mathrm{~km}$ than for greater distances. These results under- 

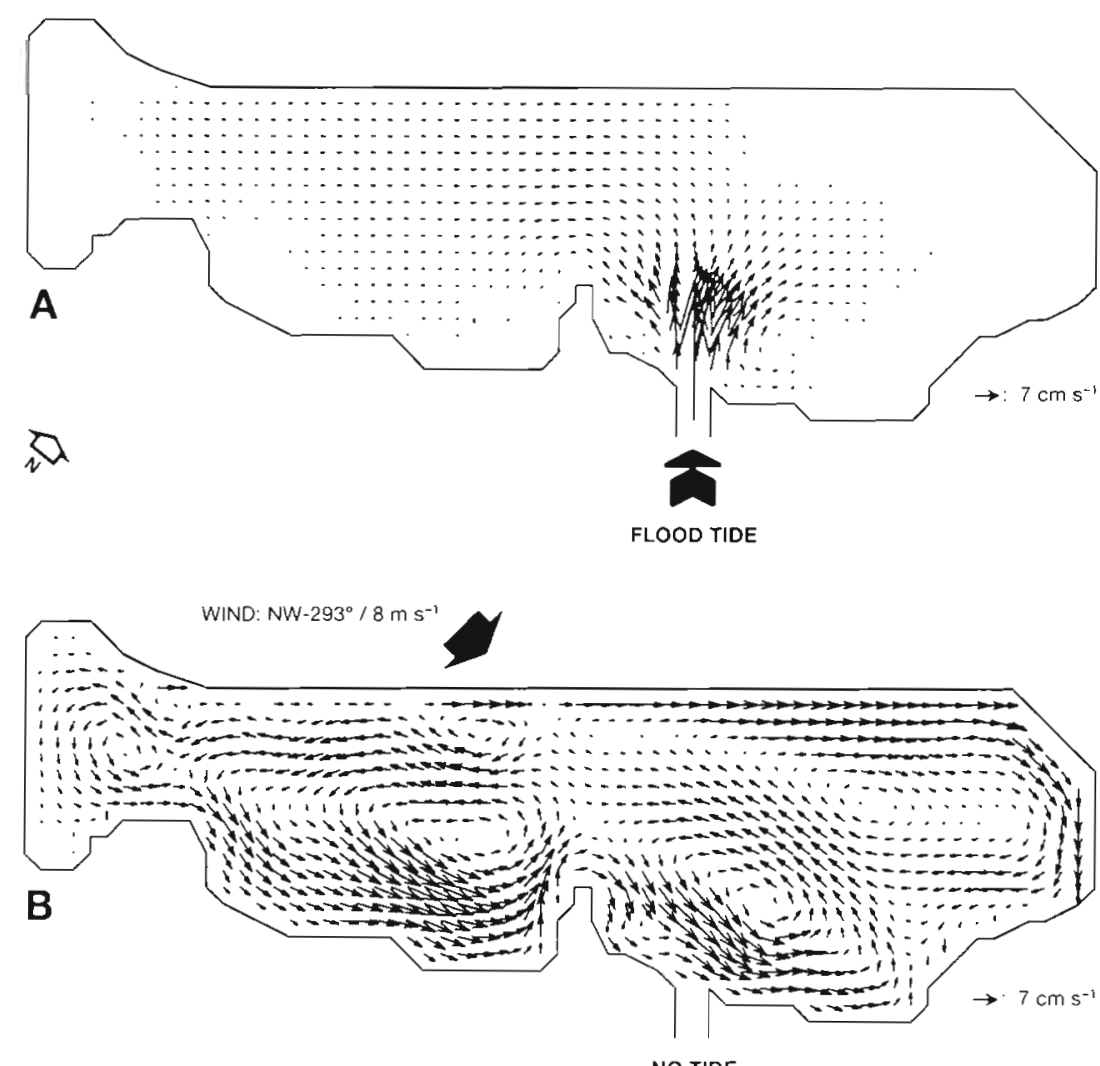

NO TIDE

Fig. 3. (A) Computed tide-induced vertically averaged current field, corresponding to the maximum of typical flood-tide. (B) Computed wind-induced vertically averaged current field, corresponding to a typical NW $\left(293^{\circ}\right)$ and $8 \mathrm{~m} \mathrm{~s}^{-1}$ stationary wind. (C) Computed current field, corresponding to both tide and wind forcings previously described acting simultaneously

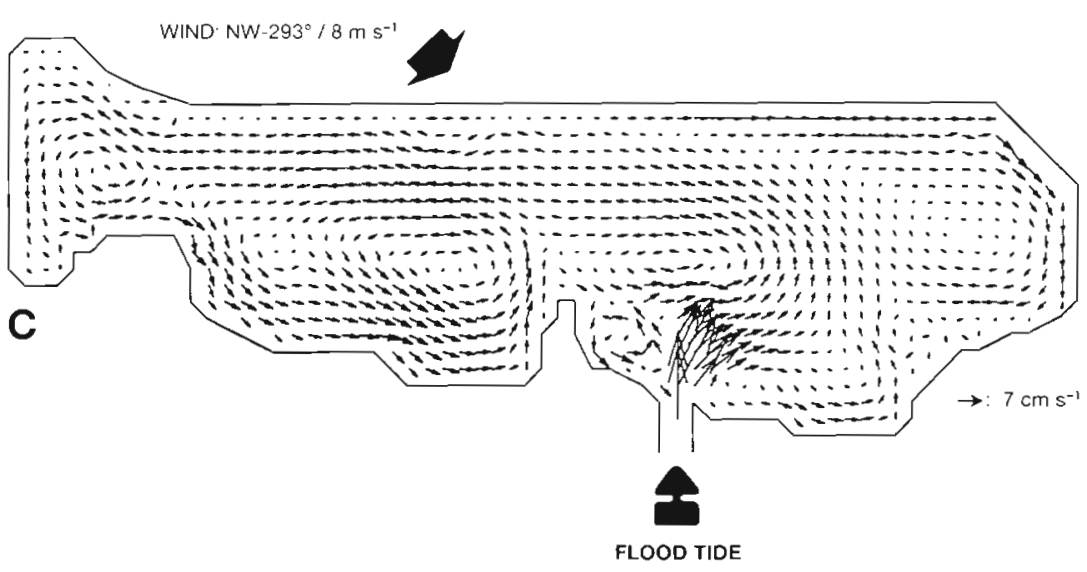

for both tide and wind forcings that correspond to the landward areas of the lagoon (Fig. 3).

The ACE algorithm was then applied to the crustacean biomass sampled in January 1974 with the environmental and hydrodynamic predictors previously described (Fig. 6)

First, transformation of environmental predictors such as distance from the sea inlet (Fig. 6A) and granulometry (Fig. 6B) showed in both cases positive relationships that respectively explained $44 \%$ and $42 \%$ of the variance. Transformation of the granulometry remained linear for the whole range of values consid- ered, but the transformation of the distance from the sea inlet (Fig. 6A) showed a non-linear relationship with a steeper slope below a threshold value of $1.6 \mathrm{~km}$ than for increasing distances. These results indicate the importance of the spatial position according to the tidal circulation and the granulometry in the development of the crustacean biomass, which benefits from landward locations far from the sea inlet, associated with the finest fraction of the sediment.

Second, transformations of hydrodynamic predictors such as the tide-induced (Fig. 6C) and wind-induced kinetic energy (Fig. 6D) showed negative curved rela- 

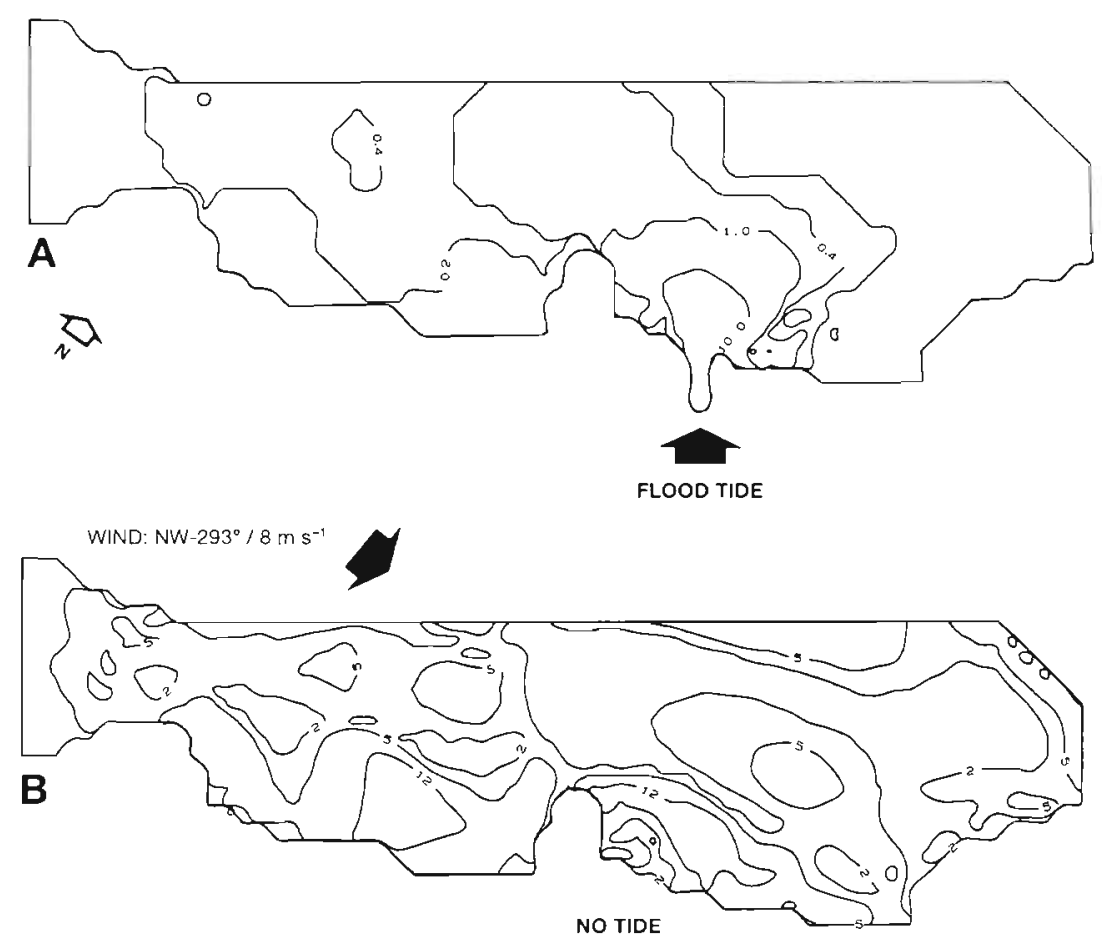

Fig. 4. (A) Spatial features of tide-induced kinetic energy isolines: $0.2,0.4,1$ and $10 \mathrm{~N}$ $\mathrm{m}^{-2}$. (B) Spatial features of wind-induced (NW, 293 ${ }^{\circ} ; 8 \mathrm{~m} \mathrm{~s}^{-1}$ ) kinetic energy isolines 2,5 and $12 \mathrm{~N} \mathrm{~m}^{-2}$

tionships that respectively accounted for $54 \%$ and $80 \%$ of the variance. These results indicate that the crustacean biomass benefits from weak kinetic energy in the water column, and especially for low values below $3 \mathrm{~N} \mathrm{~m}^{-2}$, and the detrimental effect on crustacean biomass of higher range of turbulent energy beyond this limit is emphasized for both tide and wind forcings. In addition, the wind-induced kinetic energy appears in January as the most meaningful predictor to describe crustacean biomass pattern within the lagoon.

\section{May}

The ACE algorithm was applied to the mollusc biomass sampled in May 1974 with the same environmental and hydrodynamic predictors previously considered, and the main results are presented in Fig. 7.

First, transformation of environmental predictors such as distance from the sea inlet (Fig. 7A) and granulometry (Fig. 7B) showed again in both cases negative linear relationships that respectively explained $68 \%$ and $78 \%$ of the variance. These results reinforce the beneficial effect on the mollusc development of the proximity of the sea inlet, associated with the coarse fraction of the sediment, but no distinction here can be clearly suggested between the positions below or above the limit of $1.6 \mathrm{~km}$ from the sea inlet, which was seen for the January sample. In addition, the impact of the granulometry on the mollusc biomass considerably increases in May, compared with the results obtained for the January sample (only $55 \%$ of variance explained).

Second, transformations of hydrodynamic predictors such as the tide-induced (Fig. 7C) and wind-induced kinetic energy (Fig, 7D), showed positive relationships that respectively accounted for $89 \%$ and $81 \%$ of the variance. These results remain quite similar to and as significant as those obtained for mollusc biomass of the January sample.

The ACE algorithm was applied to the crustacean biomass sampled in May 1974 with the same environmental and hydrodynamic predictors, and the main results are presented in Fig. 8.

First, transformation of environmental predictors such as the distance from the sea inlet (Fig. 8A) and the granulometry (Fig. 8B) showed in both cases positive linear relationships that respectively explained $80 \%$ and $75 \%$ of the variance. These results considerably reinforce the pertinence of the environmental predictors to explain in May the crustacean development, compared with results previously obtained for the January sample in which only $44 \%$ and $42 \%$ of variance were explained respectively for distance and granulometry (Fig. 6A, B). In addition, the results confirm the beneficial effect on the crustacean biomass of landward locations associated with fine granulometry, but without the threshold effect of the limit value $(1.6 \mathrm{~km}$ from the sea inlet) in the January sample. 

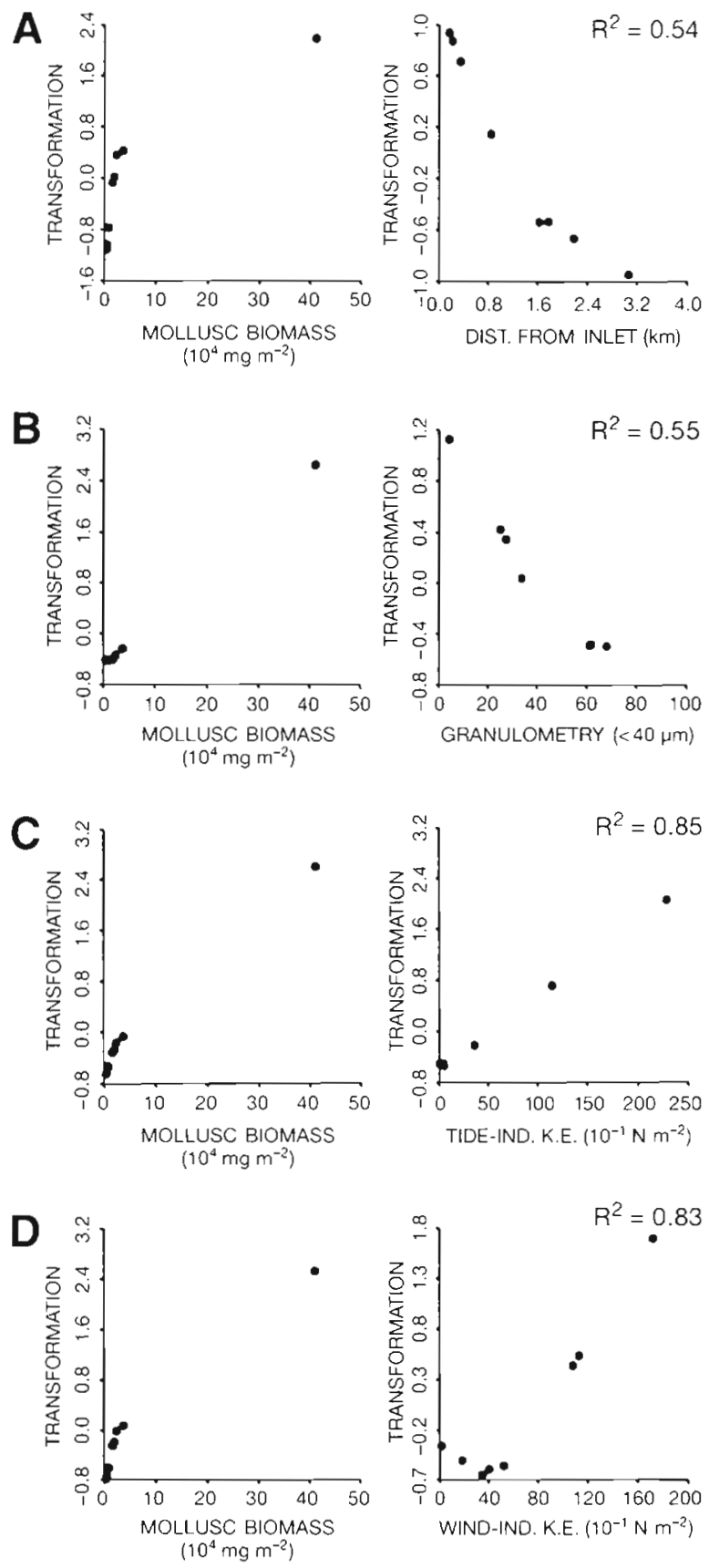

Fig. 5. ACE optimal transformations of mollusc biomass and environmental predictors (A, Distance from inlet; B. Granulometry; $C$, Tide-induced kinetic energy; D, Wind-induced kinetic energy) for January 1974 sampling

Second, transformations of the tide-induced (Fig. 8C) and wind-induced kinetic energy (Fig. 8D) showed negative curved relationships that respectively accounted for $73 \%$ and $40 \%$ of the variance. These results confirm that the crustacean biomass benefits from weak kinetic energy, as previously shown for the January sample (Fig. 6C, D). In addition, it is worth noting that the im-
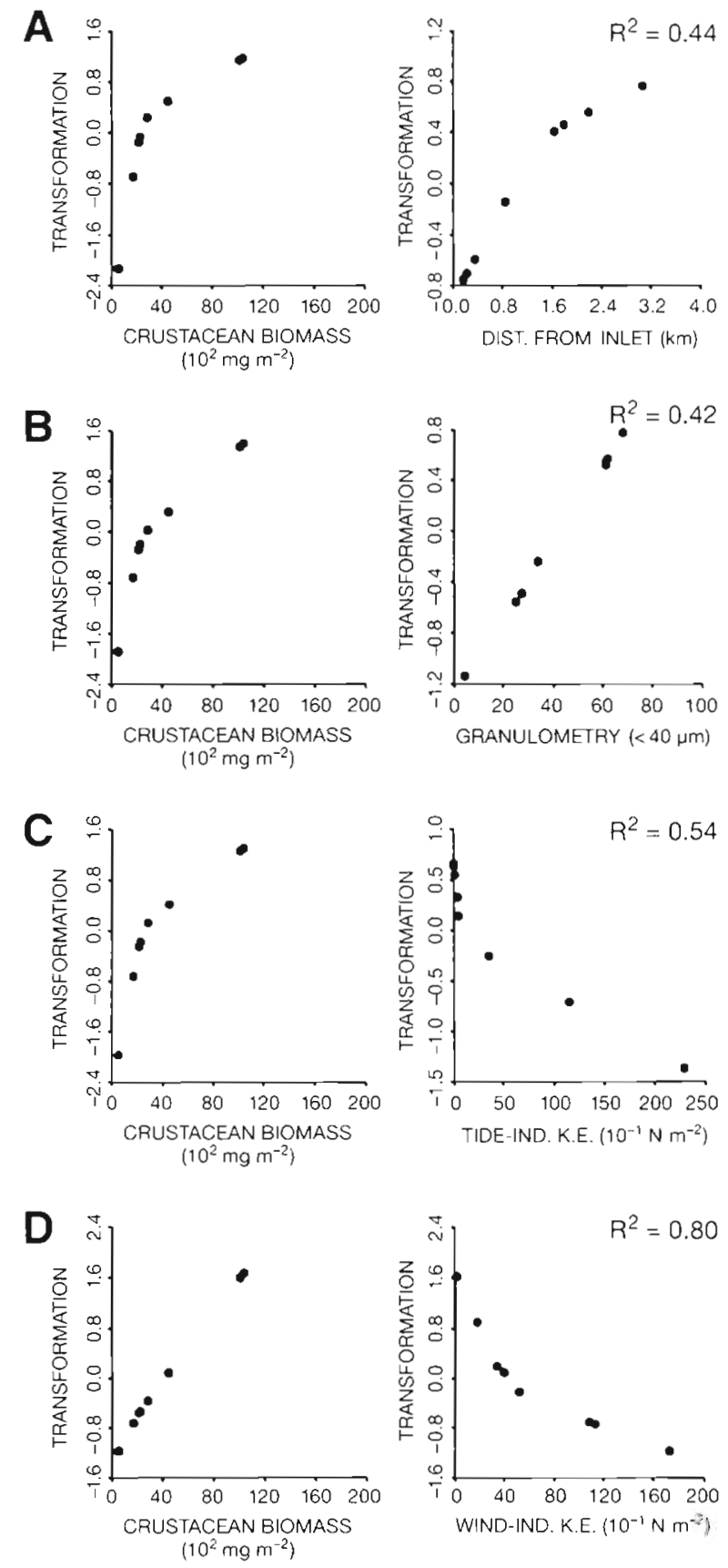

Fig. 6. ACE optimal transformations of crustacean biomass and environmental predictors $(A$, Distance from inlet; $B$, Granulometry; $C$, Tide-induced kinetic energy; D, Windinduced kinetic energy) for January 1974 sampling

pact of the tide-induced kinetic energy increases here considerably in relation to the previously described January sample (only $54 \%$ of variance explained in January) whereas the impact of the wind-induced kinetic energy broadly decreases $180 \%$ of variance explained in January). The tide-induced kinetic energy appears in May as the most pertinent hydrodynamic predictor for 

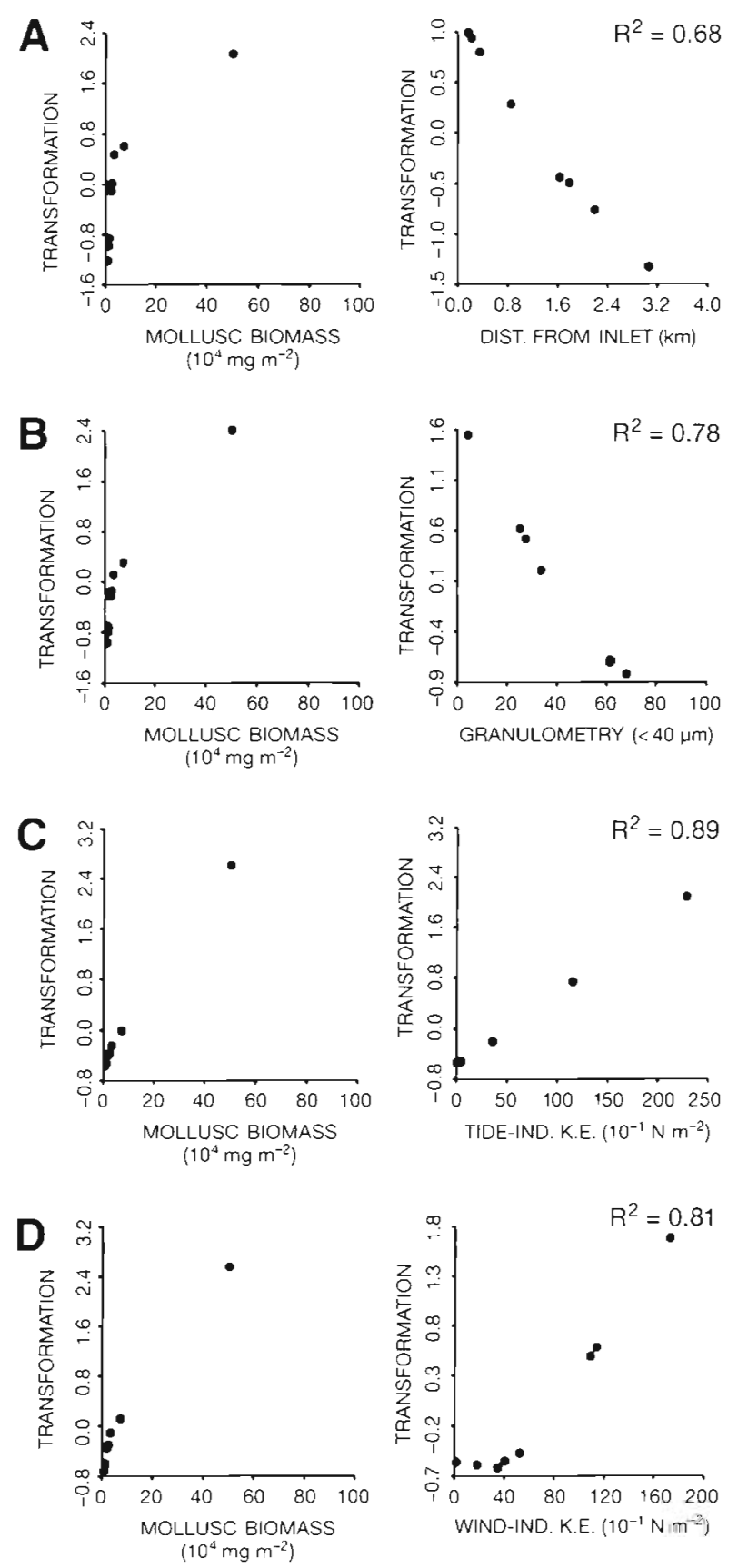

Fig. 7 ACE optimal transformations for mollusc biomass and environmental predictors ( $A$, Distance from inlet; $B$, Granulometry; C, Tide-induced kinetic energy; D, Wind-induced kinetic energy) for May 1974 sampling

crustacean biomass enhancement, in contrast to the results obtained in January.

\section{October}

The ACE algorithm was also applied to the mollusc biomass sampled in October 1973 with the same pre-
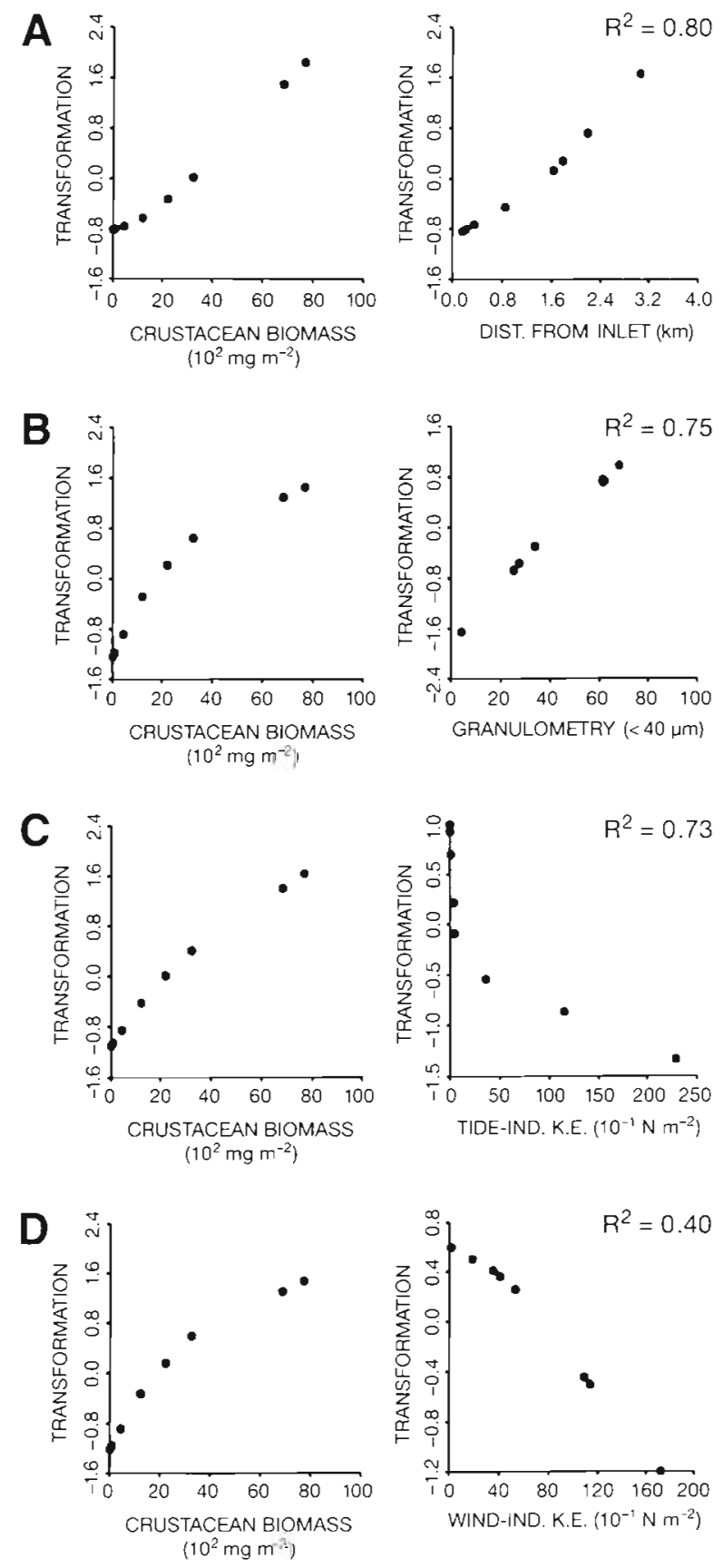

Fig. 8. ACE optimal transformations for crustacean biomass and environmental predictors ( $A$, Distance from inlet; $B$, Granulometry; C, Tide-induced kinetic energy; $D$, Windinduced kinetic energy) for May 1974 sampling

dictors previously considered, and the main results are presented in Fig. 9.

First, transformation of environmental predictors such as the distance from the sea inlet (Fig. 9A) and the granulometry (Fig. 9B) still showed in both cases negative and slightly curved relationships that respectively explained $67 \%$ and $69 \%$ of the variance. These results 

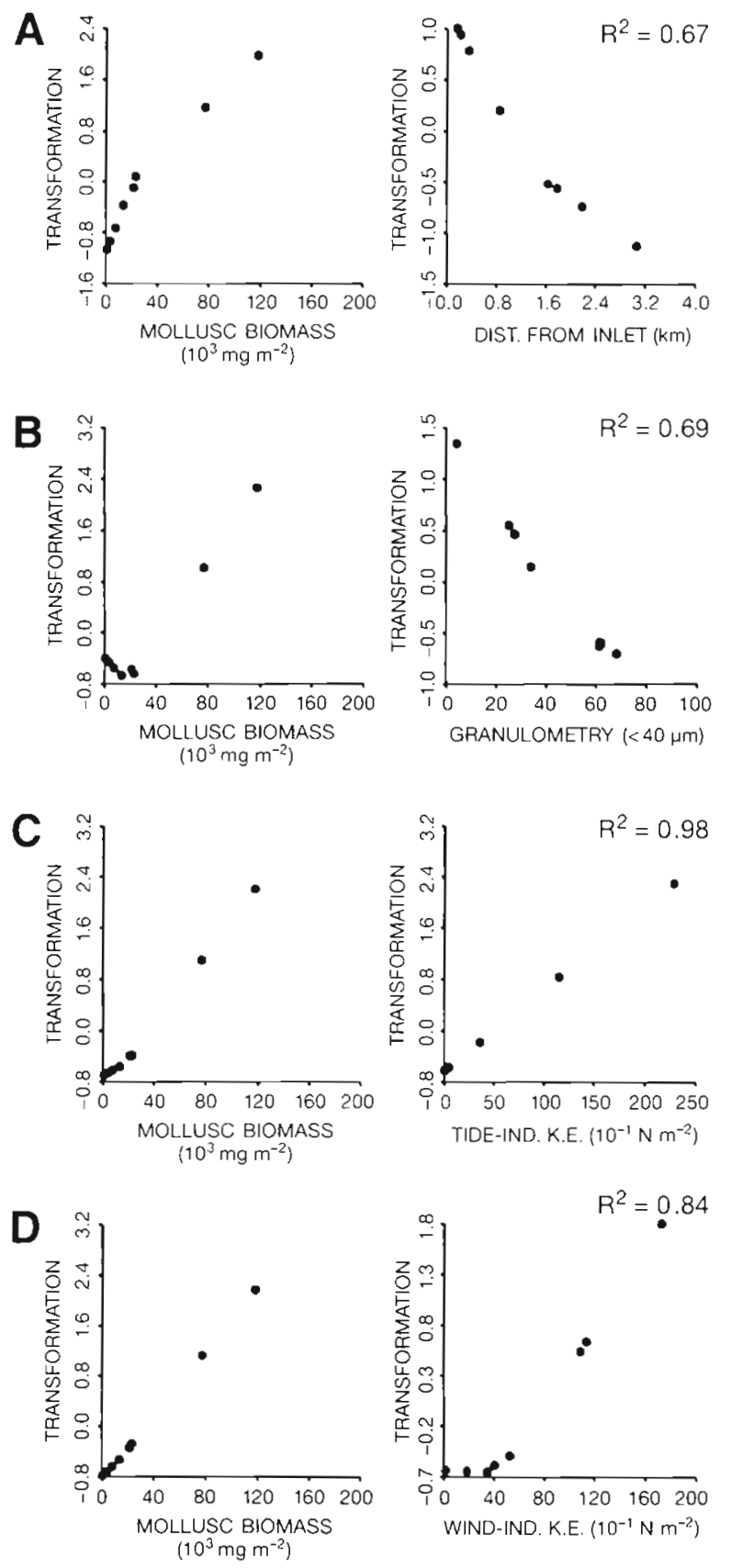

Fig. 9. ACE optimal transformations for mollusc biomass and environmental predictors (A, Distance from inlet; B. Granulometry; $C$, Tide-induced kinetic energy; $D$, Wind-induced kinetic energy) for October 1973 sampling

confirm in October the beneficial effect on the mollusc development of the proximity of the sea inlet, associated with the coarse fraction of the sediment, and a slight impact of the limit of $1.6 \mathrm{~km}$ from the sea inlet reappears here more clearly than for the May sample.

Second, transformations of the tide-induced (Fig. 9C) and wind-induced kinetic energy (Fig. 9D) showed pos- itive relationships that respectively accounted for $98 \%$ and $84 \%$ of the variance, with quite similar shapes to those previously described for the May sample, reinforcing in October the major role of the physical energy of the water column for mollusc development.

The ACE algorithm was applied to the crustacean biomass sampled in October 1973 with the same predictors, and the main results are presented in Fig. 10.

Transformation of the distance from the sea inlet (Fig. 10A) showed here a negative curved relationship that explained $40 \%$ of the variance. The slope presented here again a slight break corresponding to the distance of $1.6 \mathrm{~km}$ from the inlet, and became steeper in the landward direction than for seaward areas. It is noteworthy that this transformation function was negative in October whereas it appeared symmetrically positive in January (Fig. 7A), with a similar break at $1.6 \mathrm{~km}$ from the inlet, but an increasing slope in seaward direction.

Transformation of the granulometry presented here a weak positive relationship (Fig. 10B) with only $38 \%$ of the variance explained, and a non-interpretable minimum in the transformation for the dependent biomass.

It was important to note a considerable decline in information for this October sample, and that the only information obtained, with very weak fit, came from the distance from the sea inlet previously described (Fig. 10A), whereas the granulometry (Fig. 10B) and, in a similar way, none of the kinetic energy predictors (not shown) gave any interpretable result relating to the crustacean biomass.
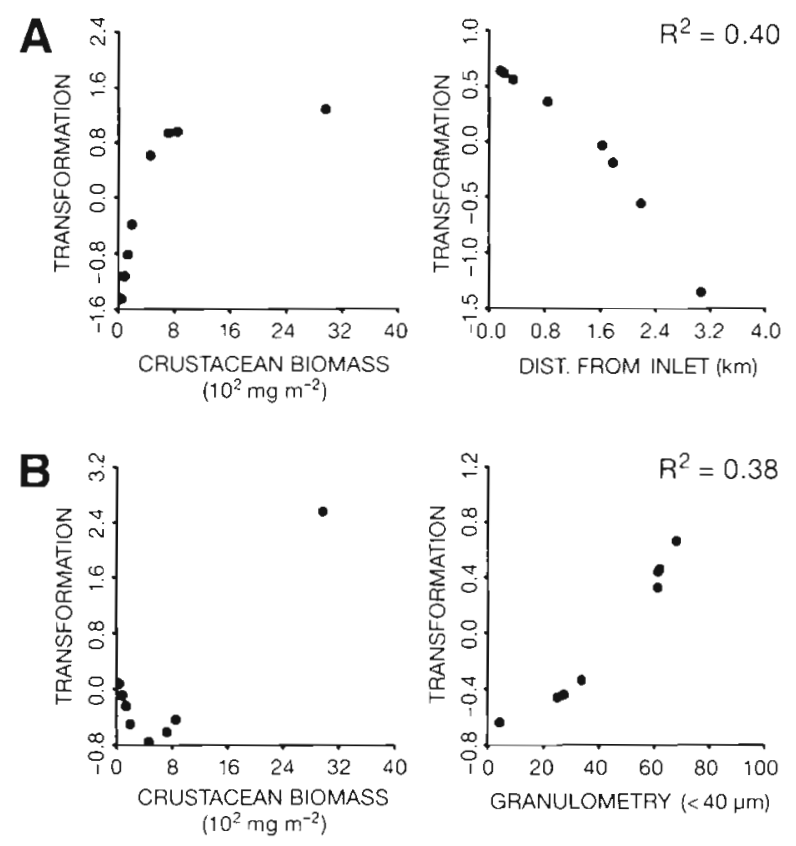

Fig. 10. ACE optimal transformations for crustacean biomass and environmental predictors (A, Distance from inlet; $B$, Granulometryl for October 1973 sampling 


\section{DISCUSSION}

The results confirm the high degree of sensitivity of benthic organisms to the environmental conditions prevailing in the shallow lagoon. This study is likely to provide a closer insight into the relationships between benthic macrofauna and sediment or hydrodynamic features, but more particularly into the spatial and seasonal variability of these relationships.

The ACE method emphasizes non-linear shapes within regressions, that clearly appear for the relationships between biomass and the distance of each station from the sea inlet (limit value: $1.6 \mathrm{~km}$ ). In addition, comparisons between similar analyses performed on each seasonal sample (January, May, October), suggest several hypotheses relating to a hierarchical succession of each environmental predictor involved in the control of the dynamics of benthos patterns for each season.

First, from a spatial point of view, the treatments of the January and May samples show a clear distinction between the partitioning of biomass between molluscs and crustaceans, in relation to specific physical conditions which differ within the lagoon, for both winter and spring periods, according to the seaward or landward positions of the sampling stations. It appears that optimal development of molluscs (highest biomasses) benefits from a high level of both tide and windinduced kinetic energy, associated with locations at the vicinity of the sea inlet and dominance of coarse sediment (Figs. $5 \& 7$ ). On the other hand, it appears that optimal development of crustaceans benefits from a low level of kinetic energy, associated with landward positions within the lagoon and dominance of fine sediment (Figs. 6 \& 8).

Settlement of marine pelecypod molluscs Ruditapes aureus, $R$. decussatus, Loripes lacteus and Scrobicularia plana occurs exclusively on the sandy sediment near the inlet. These species strongly benefit from the high energetic conditions prevailing at the seaward locations in the lagoon, associated with enhanced fluxes required to promote the development of suspension feeders (Dorey et al. 1973). In the inner lagoon, the 2 typical lagoonal species Cerastoderma glaucum and Abra ovata occur exclusively on the muddy substrate prevailing in low-energy and enriched areas.

In contrast, settlement of crustaceans Carcinus mediterraneus, Corophium insidiosum, Gammarus insensibilis, G. aequicauda and Idotea baltica occurs exclusively on fine sediment enriched with organic matter, according to the diet of these detritivorous species. In addition, at the beginning of the spring season, these mobile organisms are able to avoid detrimental environmental conditions by moving seawards to new locations influenced by marine water near the inlet (Fresi et al. 1985).
The coherent contribution of the well-correlated predictors kinetic energy (high or low level), and granulometry (coarse or fine fraction), is not surprising and consistent with the results of both numerical modelling (Figs. 3 \& 4) and field observations (Fig. 1C). In addition, the high correlation between the tide-and windinduced kinetic energy (high or low level) and the distance from the sea inlet (seaward or landward location), are quite consistent with the barotropic nature of the computed tidal circulation, and the shallowness of the inlet. Therefore, the environmental optimum found for molluscs in the vicinity of the sea inlet might be explained mainly by the coarse sediment prevailing in this energetic area influenced by strong tide- and wind-induced currents.

In addition, the location of this optimum close to the sea inlet can also reveal a specific dependence to a marine influence, and this hypothesis is consistent with previous investigations in different coastal lagoons (Nicolaidou et al. 1988, Guelorget et al. 1990). Thus, the direct hydrochemical influence of marine water might contribute to the biological organization of lagoons, in controlling the degree of restriction of inner areas with respect to the sea, which is inversely proportional to marine element fluxes at a given point (Guelorget \& Perthuisot 1992). This concept seems consistent with the 'embayment degree' proposed for coastal ecosystems in Japan (Miyadi et al. 1944, Horikoshi 1988).

An interesting result gained by using the ACE algorithm also consists in the computation of the limit distance of $1.6 \mathrm{~km}$ from the sea inlet, a spatial discontinuity between the landward and seaward poles within the lagoon. This discontinuity might correspond with the maximum spatial extension of a specific marine influence inside the lagoon, according to the local hydrodynamic conditions for flood tide circulation.

Second, from a temporal point of view, the results show the seasonal variability of the relative efficiency of each predictor in the ACE computations which differs from January to May samples.

Granulometry appears as a major predictor for both molluscs and crustaceans in May with respectively $78 \%$ and $75 \%$ of the variance (Figs. $7 \mathrm{~B} \& 8 \mathrm{~B}$ ), but only represents $55 \%$ and $42 \%$ of the variance in January (Figs. 5B \& 6B). This increasing efficiency of granulometry suggests that this environmental predictor is important in spring as hydrodynamic predictor, and confirms the major role of sediment features in explaining the seasonal variability of benthic biomass from winter to spring. This result might be related to the spring development of macrofauna for both molluscs and crustaceans, which strongly depends on the occurrence of appropriate substratum. 
In addition, tide-induced kinetic energy appears as the dominant hydrodynamic predictor for crustaceans in May, with $73 \%$ of the variance (Fig. $8 \mathrm{C}$ ), whereas this predictor only represents $54 \%$ of the variance in January (Fig. 6C). In contrast, wind-induced kinetic energy only explained $40 \%$ of the variance in May (Fig. 8D), instead of $80 \%$ in January (Fig. 6D). This increasing efficiency of tidal impact in explaining the seasonal development of crustacean biomass from winter to spring, and the decreasing efficiency of wind impact between the same periods, might be also related to recruitment processes of marine larvae, whose success strongly depends on the tidal movement of marine water within the lagoon. This hypothesis is reinforced by the similar increasing relevance of distance from the sea inlet, which in May describes $80 \%$ of the variance for crustacean biomass (Fig. $8 \mathrm{~A}$ ), instead of $44 \%$ in January (Fig. 6A), confirming the beneficial effect of landward locations to crustacean biomass enhancement (positive slope), and the attenuation of the discontinuity near $1.6 \mathrm{~km}$ from inlet. Although mollusc development from January to May does not seem sensitive to hydrodynamic predictors (Figs. 5C, D \& 7C,D), crustacean seasonal development reveals an interesting dependence on tidal motions, associated with the low energetic range localized in landward areas.

These results suggest in May an increasing ecological influence of marine waters which might promote, in spring, the recruitment success of crustacean larvae, spatially according to the presence of fine granulometry and the trajectory of the flood-tide in the inner lagoon. Thus, the benthic structure in May might reflect the reorganization of mobile crustacean organisms which migrate during the winter period from landward locations where drastic conditions prevail, toward warmer and enriched marine water masses where they temporarily could find better environmental conditions. In parallel, the simultaneous development of mollusc communities appears more strongly dependent, in the vicinity of the sea inlet, to coarse granulometry and high energetic range in the water column, but regardless whether tide or wind act as forcing processes.

Third, the results demonstrate a seasonal change of predictor impacts in ACE computations from May to October samples.

The decreasing mollusc biomasses in October do not show a notable change in the correspondence to the relative impacts of each environmental and hydrodynamic predictors, as compared to May, except for the further increasing efficiency of tideinduced kinetic energy which explains $98 \%$ of the variance in October (Fig. 9C), instead of $89 \%$ in May (Fig. 7C).
On the other hand, the drastic decrease in crustacean biomass from spring to fall can only be associated with the distance from the sea inlet, the last predictor to be considered relevant in ACE computations, with $40 \%$ of variance explained (Fig. 10A). In addition, it is of interest to note that transformation of distance is in October symmetrically shaped in comparison with May, with here a negative slope that shows the new beneficial effect of seaward positions on crustacean communities, whereas only landward locations appeared as efficient in January and May

These results suggest in October a further increasing impact of marine water circulation which might enhance locally, in the proximity of the sea inlet, the chances for benthic organisms to survive during the anoxic crises that prevail in the inner lagoon in summer. The specific impact of tidal circulation in water renewal in the vicinity of the sea inlet during summer appears more restrictive for crustaceans, which preferentially develop in landward positions, than for molluscs whose environmental optimum is localized in seaward positions

The relative impacts of dystrophic crises on benthic macrofauna seem to depend on the adaptative strategy of each zoological group considered: to burrow into the sediment or to migrate within water masses. Results obtained on this small lagoonal ecosystem illustrate the rapid reaction of benthic populations to contrasting seasonal dynamics of the physical environment. Therefore, sedentary infauna like molluscs is strongly affected by summer anoxic conditions, whereas mobile organisms like crustaceans remain able to migrate within the lagoon and find a better fit with the variability of the ecosystem (Amanieu et al. 1975, Josefson \& Jensen 1992).

\section{CONCLUSION}

These results require validation in other comparable environments, but they open the way to further investigations on spatial and temporal non-linear relationships between larval phases of benthic species and physical environment.

The first use of the present approach might be to analyse seasonal variability in typical and non-temporal physical descriptors of the lagoon environment in the hierarchy of their contributions to regressions with benthos spatial and seasonal development. Several hypotheses are therefore suggested to interpret this time-space variability in benthos-physics relationships and this hierarchical pattern of physical descriptors in relation to the ecological sensitivity and seasonal phases of each benthic species considered. 
These hypotheses, and it might be here the second interest of the present study, emphasize the central role of marine water influence, associated with the tidal excursion of water masses in the inner lagoon, from the inlet to landward positions, both to promote juveniles recruitment in spring (in landward areas) and to prevent organisms from experiencing anoxic crises in summer (in seaward areas).

These biological and trophic impacts of marine waters in a Mediterranean lagoon, despite the weak amplitude of the local tide, may be related to the shallowness of the Etang du Prevost, with $1.5 \mathrm{~m}$ maximum depth, which reinforces the barotropic tidal propagation throughout the whole area. This specific feature of shallow ecosystems can be compared with results previously obtained concerning benthos-physics relationships in a deep neighbouring lagoon with $10 \mathrm{~m}$ maximum depth, the Bassin de Thau, where wind-induced horizontal dispersion (Millet \& Guelorget 1993) substitutes for vertical turbulent kinetic energy, and windinduced stochastic recruitment (Borsa \& Millet 1992) substitutes for tide-induced seasonal input.

In addition, any research that leads to recognition of the spatial distribution of water masses not affected by dystrophic crises, by simply considering the level of kinetic energy reached within the water masses, would make a valuable contribution to decisions concerning optimal shellfish farming in shallow embayments.

\section{LITERATURE CITED}

Amanieu, M., Baleux, B., Guelorget, O., Michel, P. (1975). Etude biologique et hydrologique d'une crise dystrophique dans l'Etang du Prévost. Vie Milieu 25(2): 175-204

Amanieu, M., Ferraris, J., Guelorget, O. (1980). Organisation et évolution des peuplements des lagunes littorales. Application à la macrofaune benthique des étangs palavasiens. In: Barbault, R., Blandin, P., Meyer, J. A. (eds.) Recherches d'écologie théorique. Maloine, Paris, p. 251-277

Borsa, P., Millet, B. (1992). Recruitment of the clam Ruditapes decussatus in the Lagoon of Thau, Mediterranean. Estuar. coast. Shelf Sci. 35: 289-300

Breiman, L., Friedman, J. H. (1985). Estimating optimal transformations for multiple regression and correlation. J. Am. Stat. Ass. 80: $580-619$

Cury, P., Roy, C. (1989). Optimal environmental window and pelagic fish recruitment success in upwelling areas. Can. J. Fish. Aquat. Sci. 46: 670-680

Dorey, A. E., Little, C., Barnes, R. S. K. (1973). An ecological study of the Swanpool, Falmouth. II. Hydrography and its relation to animal distributions. Estuar. coast. mar. Sci. 1(2): $153-176$

Emerson, C. W. (1990). Influence of sediment disturbance and water flow on the growth of the soft-shell clam Mya arenaria. Can. J. Fish. Aquat. Sci. 47: 1655-1663

Fresi, E., Carrada, G. C., Gravina, F., Ardizzone, G. D. (1985) Considerations on the relationship between confinement, community structure and trophic patterns in Mediter- ranean coastal lagoons. Rapp. P.-v. Comm. int. Mer Médit. 29(4): $75-77$

Guelorget, O., Gaujous, D., Louis, M., Perthuisot, J. P. (1990). Macrobenthofauna of lagoons in Guadeloupean mangroves: role and expression of the confinement. J. coast. Res. 6(3): 611-626

Guelorget, O., Michel, P. (1979a). Les peuplements benthiques d'un étang littoral languedocien, l'Etang du Prévost (Hérault). 1: Etude quantitative de la macrofaune des vases. Téthys 9(1): 49-64

Guelorget, O., Michel, P. (1979b). Les peuplements benthiques d'un étang littoral languedocien, l'Etang du Prévost (Hérault). 2: Etude quantitative de la macrofaune des sables. Téthys 9(1): 65-77

Guelorget, O., Perthuisot, J. P. (1983). Le domaine paralique. Expressions géologiques, biologiques et économiques du confinement. Trav. Lab. Géol. Ecole Normal. Sup., Paris

Guelorget, O., Perthuisot, J. P. (1992). Paralic ecosystems. Biological organization and functioning. Vie Milieu 42(2): $215-251$

Hamerlynck, O., Mees, J. (1991). Temporal and spatial structure in the hyperbenthic community of a shallow coastal area and its relation to environmental variables. Oceanol. Acta, Spec. issue no. 11:205-212

Horikoshi, M. (1988). So-called 'embayment degree' recognized in the coastal regional ecosystem in Ryukyu and Pallau. Regional Research Workshop and Int. Symp. on the Conservation and Management of Coral Reef and Mangrove Ecosystems. Univ. of Okinawa, 9(1)

Josefson, A. B., Jensen, J. N. (1992). Effects of hypoxia on softsediment macrobenthos in southern Kattegat, Denmark. Marine eutrophication and population dynamics. In: Colombo, G., et al. (eds.) 25th Eur. Mar. Biol. Symp. Olsen \& Olsen, Fredensborg, p. 21-28

Kullenberg, G. (1978). Vertical processes and the verticalhorizontal coupling. In: Steele, J. H. (ed.) Spatial pattern in plankton communities. Plenum Press, New York, p. 43-71

Leendertse, J. J. (1984). Verification of a model of the Eastern Scheldt. R-3108-NETH. Rand Corporation, Santa Monica, $\mathrm{CA}$

Levasseur, M., Therriault, J. C., Legendre, L. (1983). Tidal currents, winds and the morphology of phytoplankton spatial structures. J. mar. Res. 41:655-672

Levasseur, M., Therriault, J. C., Legendre, L. (1984). Hierarchical control of phytoplankton succession by physical factors. Mar. Ecol. Prog. Ser. $19: 211-222$

Millet, B. (1989). Fonctionnement hydrodynamique du Bassin de Thau. Validation écologique d'un modèle numérique de circulation. Oceanol. Acta 12(1): $37-46$

Millet, B., Cecchi, P. (1992). Wind-induced hydrodynamic control of the phytoplankton biomass in a lagoon ecosystem. Limnol. Oceanogr. 37(3): 140-146

Millet, B., Guelorget, O. (1993). Relationships between benthic communities and physical environment in a lagoon ecosystem. J. coast. Res. 9(2): 378-389

Miyadi, D., Matsui, T., Habe, T. (1944). On the embayment degree and the benthic community type of the semienclosed bays. Phytosociological and Ecological Contribution, Faculty of Science, Kyoto Univ., III

Nicolaidou, A., Bourgoutzani, F., Zenetos, A., Guelorget, O. Perthuisot, J. P. (1988). Distribution of molluscs and polychaetes in coastal lagoon in Greece. Estuar. coast. Shelf Sci. 26: $337-350$

Tibshirani, R. (1988). Estimating transformations for regression via additivity and variance stabilization. J. Am. Stat. Ass. 83: 394-405 